\title{
The Organization of Political Belief Networks: A Cross-Country Analysis
}

\author{
Turgut Keskintürk \\ Department of Sociology, \\ Boğaziçi University, 34342 Bebek, Istanbul, Turkey \\ E-Mail: turgut.keskinturk@boun.edu.tr
}

Word Count: 7,918

\begin{abstract}
:
Studies on mass opinion conceptualize political ideology as an interrelated network of attitudes, beliefs and values. Using the joint dataset of European Values Study and World Values Survey collected between 2017 and 2020, I ask whether the organization of political ideology depends on the structure of political field. Consistent with the theories of social constraint, I find that in countries with high institutionalization of political parties, the organization of political opinions is more likely to be dense and consolidated. These patterns are robust to a variety of predictors between countries and the results are not sensitive to sampling variability or item selection.
\end{abstract}

Keywords: belief systems, constraint, political ideology, political parties

\section{Acknowledgement.}

This research uses data from the joint European Values Study and World Values Survey dataset. I have received numerous contributions from the conference participants at meetings organized by the American Sociological Association, Institute for Analytical Sociology, and the members of the Department of Sociology at Boğaziçi University. I am also indebted to Kevin Kiley, two anonymous reviewers, and Bahar Memiş for helping me clarify my argument. The replication files can be found at github.com/tkeskinturk/polnetworks.

This research did not receive any specific grant from funding agencies in the public, commercial, or not-for-profit sectors.

'Declarations of interest: none'. 


\section{INTRODUCTION}

In The Nature and Origins of Mass Opinion, Zaller (1992:96) defines ideology as an organizational scheme for holding together disparate political considerations. Similar formulations are common in the public opinion literature, where popular accounts conceptualize ideology as "a learned knowledge structure consisting of an interrelated network of beliefs, opinions, and values" (Jost, Federico, and Napier 2009:310). Ideology, in other words, specifies an organization or structure of sociopolitical orientations. Building on this formulation, public opinion scholars constructed a well-developed account of the social origins of belief constraint. In this view, the structural arrangement of sociopolitical beliefs is strongly tied to the political field, where political elites push mass opinion in specific directions (Slothuus and Bisgaard 2021) and provide the background for individuals to give constrained responses to survey items.

If the organization of public opinion is strongly dependent on the political field, the level of organization in public opinion should be tied to variation in institutional and political structures. However, the previous scholarship on belief constraint often preferred the opposite approach, examining individual-level variation in belief organization to suggest that those with high education and strong political awareness have highly constrained belief systems compared to the others (Zaller 1992). Thus, even though the social sources of belief organization are wellestablished, this micro-level approach missed the macro-scale contexts within which political beliefs are situated. To address this gap, this paper provides an alternative approach through an analysis of the organization of political beliefs across different countries.

In doing this, I analyze the political belief systems of 78 nations from the joint data files of the World Values Survey and European Values Study (WVS/EVS). Consistent with the theories of social constraint, I provide substantial evidence for the role of the political fields in structuring public opinion. More specifically, I find that political party institutionalization significantly predicts a more systematic organization of political beliefs. Ideologically motivated 
political parties strengthen the connections between political opinions and construct strong ties among political beliefs with different topical and systemic properties.

I organize the rest of the article as follows. First, I review the literature on public opinion, and hypothesize that political parties facilitate high belief constraint. Second, I use survey data from the WVS/EVS to construct 78 unique belief networks. I empirically examine the potential predictors of high belief organization in the cross-national context, proposing that the political fields, especially the structure of political parties, significantly predict how political ideologies are organized. In the final part, I discuss the main findings and propose future directions.

\section{PUBLIC OPINION AND MASS BELIEF SYSTEMS}

\subsection{The Social Origins of Belief Constraint}

Scholars of public opinion famously proposed that individuals are generally incoherent in their responses to survey questions. Starting with Converse's (1964:267) now-classical definition of belief systems, an extensive number of empirical works documented this phenomenon, arguing that individuals have conflicting beliefs and their responses to survey questions are susceptible to simple contextual effects (Alwin and Krosnick 1991; Converse 1964). In fact, even the most sustained challenges to this argument (mainly invoking the problems of "measurement error") show significant differences between political elites and mass publics (Converse 1964; Nie and Andersen 1974), highly educated and non-educated (Ansolabehere, Rodden, and Snyder 2008; Judd and Milburn 1980), or politically sophisticated and unsophisticated (Boutyline and Vaisey 2017; Zaller 1992). Large sections of the population thus appear to have relatively low rates of belief organization, or what social scientists call belief constraint. ${ }^{1}$

Following these questions, most studies on belief systems revolve around the problem of how individuals navigate the belief space, especially when people are exposed to contradictory

\footnotetext{
${ }^{1}$ Throughout the paper, I use the term "belief" to invoke values, attitudes, and opinions. Therefore, "belief system" refers to the domain or issue-specific and systematic organization of cultural and political orientations.
} 
patterns of cultural beliefs and practices (DiMaggio 1997; Swidler 1986). One response to this question comes from the influential "belief sampling model"2 (Zaller 1992; Zaller and Feldman 1992). According to Zaller, instead of having fixed and predetermined attitudes in a variety of subjects, individuals store a mix of different considerations. In the survey context, individuals go through "a stochastic sampling process" (Zaller and Feldman 1992:586) and average across these considerations to come up with an answer to the survey question at hand. Since the model assumes that the sampling process is dependent on the composition of one's considerations and contextual effects (e.g., priming or question wordings), it allows one to see variations among individuals in terms of how coherent and consistent their responses are. This, in turn, is derived from the overall consistencies between these considerations.

Zaller's belief sampling model situates the problem of belief constraint within the context of political consumption, which implies that the bag of considerations one might store is highly dependent on the political communications from elite actors. If these actors provide consistent and coherent messages, individuals can use simple heuristics to organize these considerations, which provides them the tools to give ideologically coherent and constrained responses.

\subsection{Cognitive Authorities in the Political Field}

If high belief constraint is tied to the composition of one's considerations, what are the central mechanisms that facilitate systematization of beliefs at the population level? In order to answer this question, we need two theoretical specifications. First, if individuals consume a variety of political or cultural considerations, how do people choose consistent considerations when faced with highly heterogeneous and conflicting messages? Second, to the extent that these messages are produced in the political field, how can political elites such as politicians, television pundits, or journalists solve the problem of producing consistent messages in the first place?

\footnotetext{
${ }^{2} \mathrm{I}$ am indebted to an anonymous reviewer to clarify this theoretical connection.
} 
The main answer to these questions lies in partisan identification. First, individuals adopt simple partisan heuristics to navigate the belief space and their partisan identities help them to selectively consume the information flow from the elites (Zaller 1992). Instead of asking which political considerations I should believe, people ask the social question, “which team am I on?" (Boutyline and Vaisey 2017:1378). This becomes salient once we see that even people's local environment stands relatively thin compared to national politics (Lindner and Houle 2021), and one's political considerations are strongly responsive to the partisan cues (Goren, Federico and Kittilson 2009). Moreover, political parties provide leadership cues and shape information flow (Zaller 1992), reduce information costs (Gordon and Segura 1997), generate partisan alignment if novel issues arise (Carmines and Stimson 1986) and help people use cheap heuristics to find the "correct" stances (Martin and Desmond 2010). Second, partisan identification also resolves how political elites coordinate in providing consistent messages. To use Martin's (2002) fitting phrase, political parties are "cognitive authorities" that put pressure on political elites to agree on political issues and produce beliefs that have mutually supporting implications (872). Thus, extending the logic of cognitive authorities to the national level, political parties operate as the defining centers for organizing and structuring the belief space (see Boutyline 2022 who argues that political positions might be bundled according to the information streams from elites).

There are two implications of these propositions. First, the theoretical implication is that ideologically motivated parties work similar to religious preachers and ideologues, helping cohere political considerations and organize consistent cues for navigating the belief space. This, in turn, should systematize different political beliefs, tying ideological considerations to policy questions and social attitudes. Second, the empirical implication is that the structural properties of political beliefs should vary according to the organization of political parties.

\subsection{The Organization of Political Parties}

What, then, are the main mechanisms that help political parties to increase belief organization? 
I propose the ideological institutionalization of political parties, defined as the degree to which political parties in the political field have internal ideological coherence, strong connections to their constituencies, and organizational capacities. More concretely, ideological institutionalization refers to the organization of political field around clearly demarcated actors and strongly institutionalized rules, frames, and vocabularies (Lizardo 2019). This leads to "clear, plentiful, and useful" political information, which in turn increases the chances of producing and receiving consistent messages. Hence, "the citizenry should, on average, appear more sophisticated" in the relevant political scene (Gordon and Segura 1997:143).

The proposed components of ideological institutionalization have distinct but compatible effects on belief constraint. First, the extent to which political parties have internal ideological coherence increases the chances of consistent messages. This helps the citizens to grab the most salient consideration when confronted with an issue and easily adopt the partisan stance when the political topic is relatively distant (Zaller 1992; Zaller and Feldman 1992). Second, partisan messages have more chance to disseminate if political parties keep strong political ties to their constituents, meaning that the positions of the political parties in terms of national policies have more opportunities to diffuse if parties and their constituencies have strong relations (Slothuus and Bisgaard 2021). Third, these mechanisms strongly depend on the organizational capacities of the political parties. Hence, political parties need capable organizational structures in order to efficiently coordinate the dissemination of values and opinions.

These components are analytically distinct, but they are most likely to correlate robustly in the empirical settings. Since political parties have varying funding opportunities and historical ties to different sectors, parties that have high organizational capabilities are likely to have more powerful political communication channels and high impact on the public opinion fields. The most essential argument is that as far as the political field itself has a clear and ideologically stable organization, this should affect how citizens structure their opinions accordingly. 


\subsection{Alternative Explanations and Scope Conditions}

There are at least there potential objections to this framework. First, the claim that the political field has an effect on belief constraint might be valid, but there can be other factors that mitigate the importance of ideological institutionalization. For instance, the number of parties operating in the national political system might be much more important than the characteristics of these parties. After all, an increase in the number of effective political parties (Laakso and Taagepera 1979) can destabilize the ideological positions through cross-cutting ties (DellaPosta 2020). In similar fashion, political polarization can increase belief constraint through partisan alignments (Baldassarri and Gelman 2008; Kozlowski and Murphy 2020). The same importance might be ascribed to the information structures and the position of the media (Zaller 1992), as it can have an explicit effect on the dissemination and composition of the political messages.

Second, political belief constraint can vary according to the citizen attributes. One potential confounder is educational attainment, as it is well-established that individuals provide more constrained survey responses if they have high education (Converse 1964; Fishman and Davis 2021; Judd and Krosnick 1982; Judd and Milburn 1980; Peffley and Hurwitz 1985). Similarly, an argument can be made for the political and civic activities of the citizens. To the extent that the countries have vibrant civil societies (e.g., political engagement and associational activities) and high civic engagement, there can be a better chance of belief constraint. Operationally, this can be an alternative proxy for the political interest and sophistication (Zaller 1992).

The final potential objection involves population heterogeneity. The use of correlational measures at the national level makes the assumption that a single constraint-generating process affects the whole population, which could obscure heterogeneities across different subpopulations (Baldassarri and Goldberg 2014; Goldberg 2011; but see Boutyline and Vaisey 2017 for an alternative view that no such heterogeneity exists). There can be linguistic, ethnic, and religious diversities within countries. More significantly, these differences can be mirrored in the 
survey instrument itself, which can obscure the different meanings attached to each item for each population group in a country (Baldassarri and Goldberg 2014). Even though the crossnational approach simplifies these processes and allows one to establish comparisons between units in higher levels of aggregation, these results might be sensitive to internal heterogeneities, and the assumption of a single dominant process of belief formation might be untenable.

These counter-explanations might affect the theoretical framework outlined above. Thus, I consider each objection in the upcoming empirical analyses.

\section{ANALYTIC STRATEGY}

In order to test these ideas empirically, I used data from the World Values Survey and European Values Study (EVS/WVS 2020). In the 2017 and 2020 periods, EVS/WVS surveyed 81 unique countries (35 from EVS and 51 from WVS), ${ }^{3}$ collecting representative data with nearly 135,000 individuals. Each questionnaire included diverse opinion items, ranging from economic values and political culture to moral and cultural issues. Both organizations developed their questionnaires independently, the overlapping items of which were combined in an EVS/WVS variable correspondence sheet. I screened the list of all joint variables and kept 32 belief items relevant to political issues, including economic redistribution, government spending, immigration, gender norms and political organization. The complete list of countries, corresponding surveys and the opinion items are documented in the Appendix.

\subsection{Measuring Political Belief Constraint}

Building on the previous literature (Baldassarri and Gelman 2008; Boutyline and Vaisey 2017; DellaPosta 2020), I obtained the zero-order squared correlation coefficients ${ }^{4}$ between each pair

\footnotetext{
${ }^{3}$ Five countries are covered in both datasets. These are Germany, Romania, Russia, Serbia, and Ukraine. The data from each survey are then pooled in the joint EVS/WVS data file.

${ }^{4}$ To obtain correlation coefficients, I used polychoric correlations for ordinal variables, Pearson correlations for interval variables, and polyserial correlations for ordinal and interval variables. The variables with seven or fewer responses are treated as ordinal variables. I estimated correlation coefficients with complete pairwise observations,
} 
of political belief items for each country, resulting in 496 correlation pairs per unit and 40,176 total correlation pairs for all countries. ${ }^{5}$ The correlation coefficients range from nearly 0 to as high as $0.98(\mu=0.03$ and $\sigma=0.07)$. I constructed 81 networks from these belief pairs and then averaged the edge weights to have the final measure of constraint for each network.

\subsection{Measuring Ideological Institutionalization}

Measuring the ideological institutionalization of the political parties necessitates three items to tap the relevant institutional components: (a) internal ideological coherence, (b) strong connections to constituencies, and (c) organizational capacities. The most pertinent measures for these questions, as far as the items that I know of, can be obtained from the "Varieties of Democracy" (V-Dem) dataset (Coppedge et al. 2020). V-Dem is an independent research institute collecting cross-national data from an international team of 3,200 experts. These experts provide various ratings on an extensive number of political items with such diverse issues as electoral systems, the form of democratic institutions, and the structure of political parties.

I used five variables from this dataset. In order to measure internal ideological coherence, I used two distinct measures: (1) legislative party cohesion, which asks whether the party members vote with their parties all the time on important bills or partisan discipline is weak among legislative members, and (2) distinct party platforms, measuring whether the major parties have publicly available ideological manifestos. These items tap two components: the programmatic coherence of the political parties and the agreement of politicians over shared political goals. I measured the relations between political parties and their constituencies with (3) party linkages item, which quantifies the degree to which these two actors have shared goals in terms of values and programmatic policies, rather than reward-based clientelist relations. To measure the final

\footnotetext{
meaning that I used every information for each pair. In order to relax the normality assumption, I used nonparanormal transformation from R's huge package to implement Gausianization.

${ }^{5}$ In 11 countries, the question of "political ideology" (the position on the left-right scale) is not asked. I controlled for this omission in the upcoming models, and dropping this item did not change the overall results. This omission decreased the total number of correlations to approximately 38,000 .
} 
dimension, organizational capacities, I used (4) party organizations (whether the central parties have permanent national offices) and (5) party branches (the local reach of the parties). ${ }^{6}$

As expected, these items are highly correlated (with correlation coefficients ranging from 0.6 to 0.9 for most item pairs). Considering that ideological institutionalization conceptualizes a univariate construct, I averaged these items and generated an additive scale. I then validated this choice. First, I implemented principal component analyses, the results of which show that the items load onto one underlying factor (factor loadings are all above 0.5) with an eigenvalue equal to 3.36, and the resultant index explains $67 \%$ of the variance. ${ }^{7}$ Similar results are obtained from the reliability tests (Cronbach's $\alpha=0.86$ ). I also checked whether there are idiosyncrasies in certain periods and correlated the item with an alternative index that uses the average values between 2000 and 2017, though these scales are highly correlated (0.98). This item, what I call ideological institutionalization, provides the main predictor for the central proposition. ${ }^{8}$

\subsection{Control Variables}

I also included several control variables. The first set of controls involves the characteristics of the political fields. First, replicating Laakso and Taagepera's (1979) well-known method which provides an effective number of parties (i.e., the number of political parties adjusted according to their electoral success), I controlled for the effective count of political parties. The majority of the values come from an extensive study of Gallagher's (2020) online election indices data. I hand-calculated the 13 missing cases from the most recent election results. Second, I used two scales from the V-Dem dataset. To control the potential effects of media on how political information is diffused, I used an alternative sources of information index that quantifies the extent to which media is differentiated. The second scale (political polarization) measures

\footnotetext{
${ }^{6}$ These items are used for measuring party institutionalization between 1900 and 2018 in the V-Dem dataset. See the extensive discussion of the index in Bizarro, Hicken and Self (2020).

${ }^{7}$ The predicted factor scores have a correlation of more than $99 \%$ with the averaged scale.

${ }^{8}$ To validate the scale even further, I used partial least squares regression models for the upcoming models. I cross validated different specifications and the one-component item consistently resulted in the best model.
} 
whether the country is politically polarized between two groups along antagonistic lines.

The second set of controls involves the citizen attributes. In order to measure educational attainment, I used the mean education scores of the respondents in the EVS/WVS dataset. ${ }^{9}$ To account for political activism and civic membership, I used EVS/WVS values once again, and computed a political activism (Cronbach's $\alpha=0.79$ ) and a civic membership scale (Cronbach's $\alpha=0.82$ ). ${ }^{10}$ Similar items using alternative sources (such as V-Dem) produced comparable and reliable estimates, which is why I used the mean EVS/WVS scores instead.

The final set of control variables is intended to account for the differences within national units and the potential differences between survey instruments. One potential confounder is the ethnic and religious fractionalization within countries, as it might be possible that ethnically or religiously fractionalized polities have less stable and coherent positions. To account for these possibilities, I included an index from the Historical Index of Ethnic Fractionalization Dataset, measuring the probability that two randomly drawn individuals are not from the same ethnicity, and an additional index that measures religious fractionalization (see Alesina et al. 2003 for the details). To control the differences between survey instruments, I included the mode of survey collection (online surveys or offline surveys), whether the instrument is conducted in single or multiple languages, and the sample size. The descriptive statistics for the predictors used in the following regression models are presented in the Appendix. ${ }^{11}$

\subsection{Analysis Steps}

The following analyses proceed in four steps. First, I examine the variation in the organization

\footnotetext{
${ }^{9}$ Using an alternative index from the United Nations Development Program did not change the results.

${ }^{10}$ To calculate political activism scale, I first summed four variables (signing petition, joining in boycotts, attending demonstration and joining unofficial strikes) and then calculated the average scores for all countries. Similarly, I added eleven dichotomous items for the civic membership scale (belonging to religious organizations; education, arts, music and cultural activities; labor unions; political parties; environmental groups; professional associations; sports groups; consumer groups; charitable organizations; self-help groups; and non-mentioned other groups).

${ }^{11}$ There are missing observations at the country-level (Andorra, Macau and Puerto Rico), which reduces the number of countries used in the following analyses to 78 .
} 
of political beliefs and evaluate the evidence in favor of ideological institutionalization. In doing this, I use mean squared correlations to have an estimation for network-level political belief constraint. I then estimate OLS regression models to adjudicate whether strong ideological institutionalization is associated with increased belief constraint. Since the number of data points is low, I use Bayesian Model Averaging (henceforth, BMA) to decide on the best fitting models (Raftery 1995). Second, I use nonparametric bootstraps to examine the potential sampling variabilities (Boutyline and Vaisey 2017). I generate 1,000 bootstrapped samples for each country, and evaluate the trends in these samples. Since the selection of opinion items can influence the results, I construct 2,000 additional samples (1,000 samples by randomly dropping $25 \%$ of the items and 1,000 samples by randomly dropping $50 \%$ of the items) and replicate all the analyses. Third, I use multi-level models to validate the OLS regressions. Then, I categorize the variables into two - one for symbolic beliefs, i.e., those that pertain to ideological attitudes, social values, and labels, and one for operational beliefs, i.e., those that can be implemented in certain governmental policies (Brandt, Sibley, and Osborne 2019). This allows me to validate whether the proposed relationships are sensitive to item-specific relations. In the final section, I analyze the within-country heterogeneities across educational differences.

\section{RESULTS}

Figure 1 presents the relationship between graph level political belief constraint and ideological institutionalization across 78 countries. The constraint levels range from 0.01 to $0.06(\mu=0.03$ and $\sigma=0.01$ ), and the figure shows high variation in the organization of political belief systems. It is evident that ideological institutionalization and belief constraint are highly correlated (the Pearson's $r=0.65$ ) and the cubic spline-smoothed function shows an almost linear relationship. Thus, the first inspection confirms the initial proposition: the structure of major political parties has strong associations with the amount of belief organization in the public. 


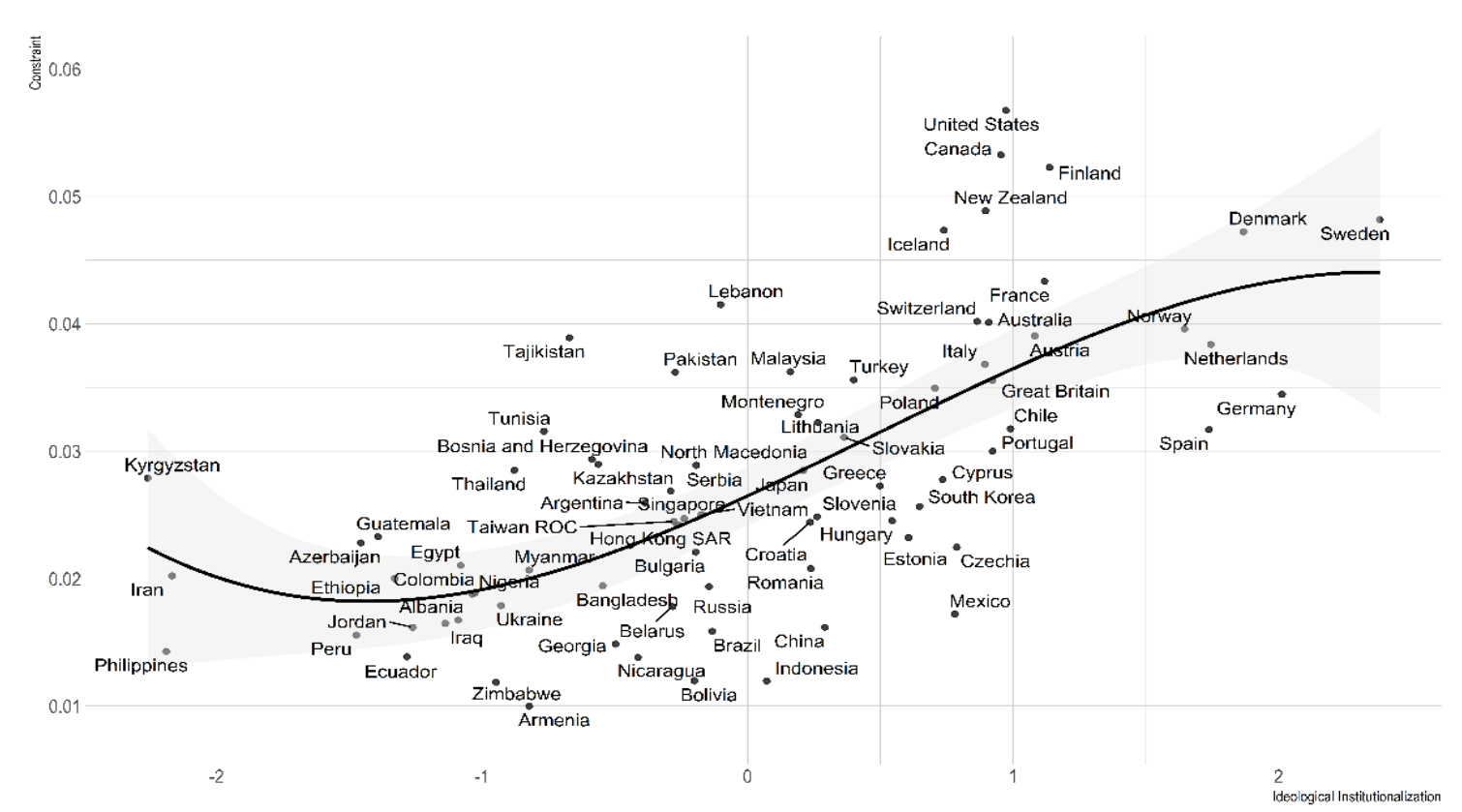

Figure 1: Relationship Between Ideological Institutionalization and Belief Constraint

Note: Each point represents country-level belief constraint. Shaded regions represent 95\% confidence intervals.

Table 1 provides the OLS regression results and the corresponding BMA probabilities of coefficients. Overall, the results reveal substantial evidence that favors the central proposition. BMA estimations show that the best model consists of two central variables, and the probability that the coefficients are not equal to zero is more than $90 \%$ in both cases. Considering that the number of observations is fairly low, the coefficient estimate for the main variable is even more impressive. Looking at the regression diagnostics, the reduced model fits well, and the ShapiroWilk test confirms the normality of the residuals $(\mathrm{W}=0.97, p>0.05)$.

Substantially, these results confirm that the variation in the organization of sociopolitical beliefs can be predicted from the organization of political fields. This does not mean that people update their beliefs in response to changing period effects (Kiley and Vaisey 2020) nor does it mean the changes in politics directly translate into changes in public opinion. After all, opinion structures and political structures are co-constitutive, each harboring different mechanisms for shaping the other. Rather, these results show that the cohesion of political ideologies is associated with the relative cohesion of the political field. Since clear signals from political elites and cognitive authorities might strengthen the tightness of opinion reporting, the robustness of 
political environments can induce high constraint among individuals.

Table 1: OLS Regression Models Predicting Belief Network Constraint

\begin{tabular}{|c|c|c|c|}
\hline Predictors & Full Model & Reduced Model & $p \neq 0$ \\
\hline Ideological Institutionalization & $\begin{array}{l}0.389 * * \\
(0.133)\end{array}$ & $\begin{array}{l}0.459 * * * \\
(0.100)\end{array}$ & 1.00 \\
\hline Country-Level Political Activism & $\begin{array}{l}0.491 * * \\
(0.161)\end{array}$ & $\begin{array}{l}0.449 * * * \\
(0.116)\end{array}$ & 0.99 \\
\hline Mean Educational Attainment & $\begin{array}{c}0.064 \\
(0.133)\end{array}$ & & 0.10 \\
\hline Alternative Sources of Information & $\begin{array}{r}-0.093 \\
(0.175)\end{array}$ & & 0.07 \\
\hline Country-Level Civic Membership & $\begin{array}{c}0.062 \\
(0.130)\end{array}$ & & 0.05 \\
\hline The $N$ of Effective Political Parties & $\begin{array}{r}-0.037 \\
(0.104)\end{array}$ & & 0.03 \\
\hline Country-Level Political Polarization & $\begin{array}{r}-0.069 \\
(0.126)\end{array}$ & & 0.07 \\
\hline Ethnic Fractionalization & $\begin{array}{c}0.031 \\
(0.129)\end{array}$ & & 0.03 \\
\hline Religious Fractionalization & $\begin{array}{r}-0.116 \\
(0.129)\end{array}$ & & 0.06 \\
\hline Survey Instrument Controls & + & + & + \\
\hline $\mathrm{N}$ & 78 & 78 & - \\
\hline Adjusted $\mathrm{R}^{2}$ & 0.54 & 0.57 & - \\
\hline
\end{tabular}

Note: Coefficients are standardized. Heteroskedasticity-consistent standard errors are in parentheses. $p \neq 0$ refers to the probability that the variable is not 0 . The missing countries are Andorra, Macau and Puerto Rico. All models control for the inclusion of political ideology, the mode of survey collection, sample size, and survey language. $* * * \mathrm{p}<0.001, * * \mathrm{p}<0.01$.

\subsection{Sampling Variability and Item Selection}

Having established the contextual differences between countries, I turn to sampling variability and item selection. In order to assess sampling variability, I used non-parametric bootstrapping to evaluate the statistical significance of the regression results (Boutyline and Vaisey 2017). In 1,000 bootstrap iterations, I gathered 1,000 samples for each unit of analysis, and followed the same strategy outlined before to estimate belief constraints. Figure 2 presents the main results. The left panel shows the distribution of $t$-values from bootstrapped regressions, confirming that 
ideological institutionalization is significantly associated with belief constraint in all cases (the coefficients are also in the expected direction). The right panel plots the predicted values from the cubic spline-smoothed function that uses the mean scores and $95 \%$ confidence intervals of bootstrapped belief constraints. Substantially, non-parametric bootstraps reveal that the results are not sensitive to sampling variability, substantiating the central proposition.

The previous analyses used the EVS/WVS items that pertained to political issues. While it is true that these variables are relatively comprehensive, it is also true that there can be some item selection effects. To test this possibility, I systematically changed the set of variables used in the constraint estimations. In 2,000 random samples, I created 1,000 networks for each unit with $75 \%$ of the variables ( 24 out of 32 ) and 1,000 networks with $50 \%$ of the variables (16 out of 32). In doing this, I followed the same procedure, estimated the correlations, calculated their constraint levels, and compared the country-specific estimates. Figure 3 depicts the distribution of $t$-values. The left panel shows that ideological institutionalization is still strong and statistically significant in all random samples (the coefficients are in the expected direction, too) while the right panel shows that $99.5 \%$ of the comparisons reveal statistically significant effects from the main predictor even when the number of nodes is reduced to half. Overall, these estimations show that the results do not seem sensitive to sampling or item variabilities.
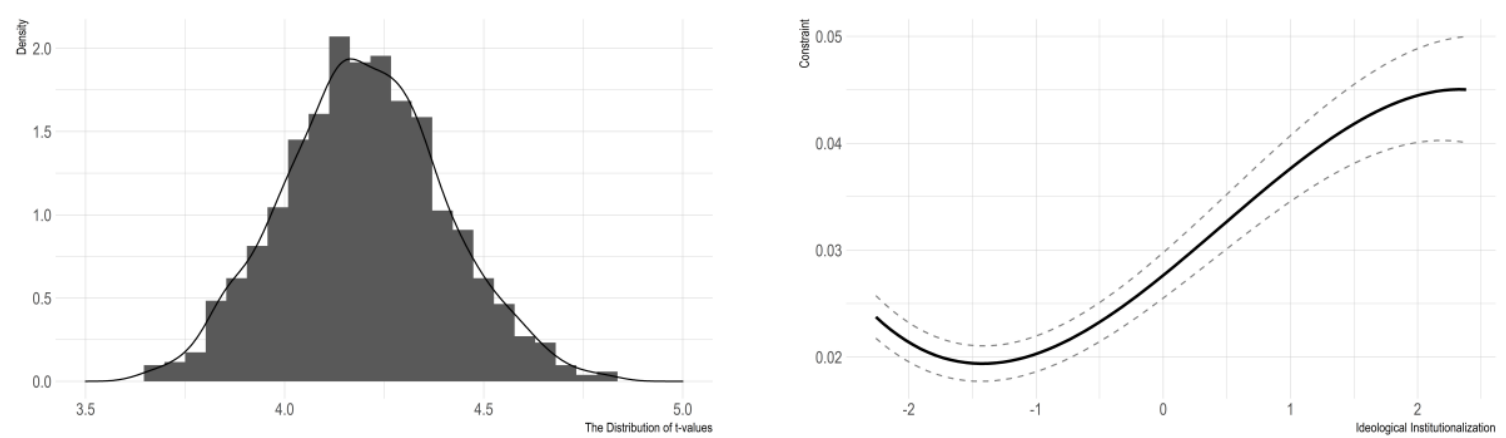

Figure 2: Bootstrapped Replications of Belief Constraint Note: The left panel plots the distribution of $t$-values from 1,000 robust regression models. The right panel shows the cubic spline-smoothed function from the bootstrapped mean values of belief constraints. 

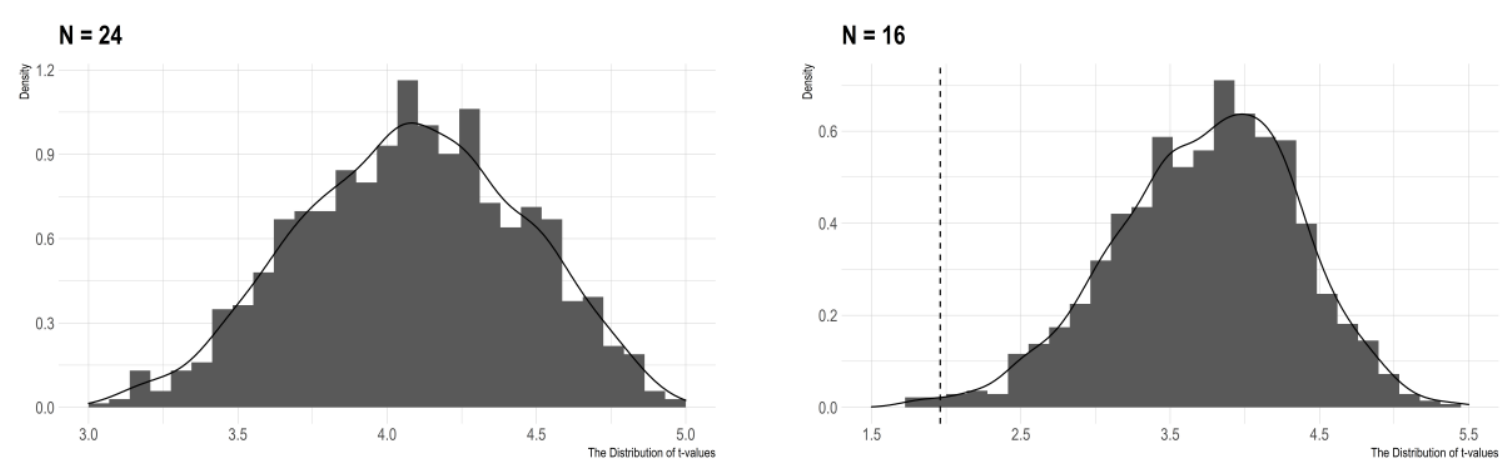

Figure 3: Item Selection Effects

Note: The left panel plots the distribution of $t$-values from 1,000 samples that randomly choose 24 out of 32 items, while the right panel plots $t$-values from 1,000 samples that randomly choose 16 out of 32 items.

\subsection{Multilevel Models and Item Heterogeneity}

It is important to note that the previous conclusions are estimated at the graph level, which can conceal within-network heterogeneities across the countries. In order to confirm whether these results are applicable at the item-pair level, I also estimated multilevel mixed-effects regression models. In doing this, I evaluated three models and selected the varying intercepts and varying slopes specification. ${ }^{12}$ Figure 4 shows the distribution of slopes across 496 correlation pairs. In more than $97 \%$ of the pairs, the slopes are positive or near zero, which confirms that the results obtained in the pooled regressions are also replicable at the edge-level.

An alternative possibility that might qualify the results is item heterogeneities. The recent work on belief system dynamics demonstrates that items have different properties according to their substantive meaning, i.e., those with symbolic meanings (items that pertain to values and labels) have substantial influence in contrast to those with operational meanings (governmental policies). One possible repercussion of this is that ideological institutionalization might occur simply because political parties feed certain symbolic concerns, leaving other beliefs relatively untouched. If this is true, then the effects of ideological institutionalization are heterogeneous,

\footnotetext{
${ }^{12}$ The BIC scores are 65007 for the varying intercepts model, 60588 for the varying intercepts and varying slopes model (fixing political activism), and 58883 for the varying intercepts and varying slopes model (varying political activism along with the ideological institutionalization variable). I present the results from the third estimation.
} 
and solely dependent on the specific contents of the political beliefs.

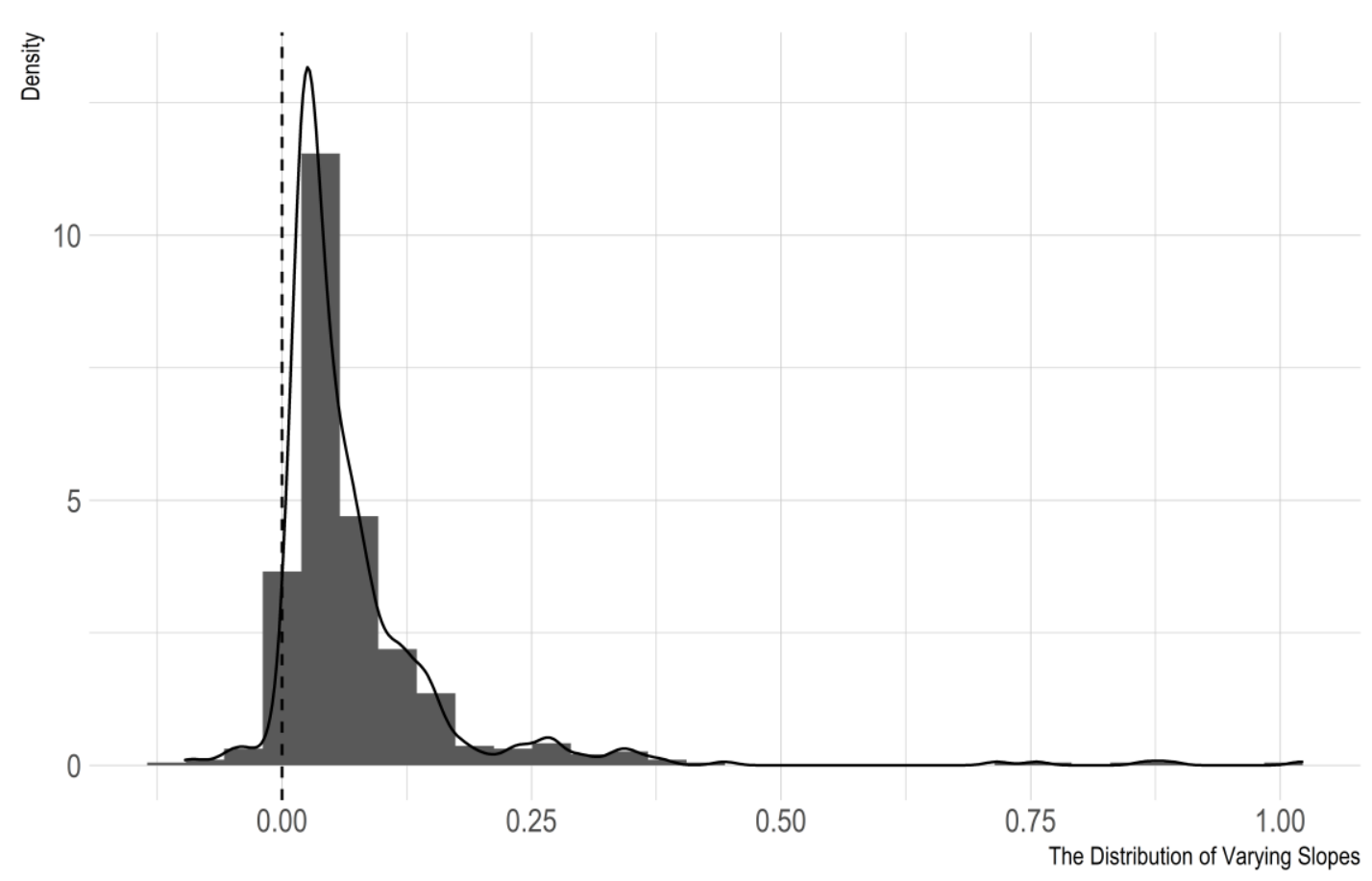

Figure 4: The Distribution of Varying Slopes

Note: The coefficients from the varying-intercept varying-slope models $(\mathrm{N}=496)$.

In order to account for this possibility, I labeled 32 items as symbolic or operational (see the Appendix for the full list). Then, I calculated the mean constraints for each level, looking at belief pairs either among symbolic or operational beliefs, or between beliefs. Figure 5 shows the country-specific mean values of political beliefs. In line with the previous work, it is evident that correlation pairs among symbolic beliefs have higher constraint than the others. Of course, the question is whether ideological institutionalization has differential effects across these item levels. Considering that distinct levels have belief-pair variability, I standardized the correlation coefficients within categories and compared the trajectories of belief constraint with respect to ideological institutionalization. The results are presented in Figure 6, which confirms that ideological institutionalization has similar trajectories across item levels. 


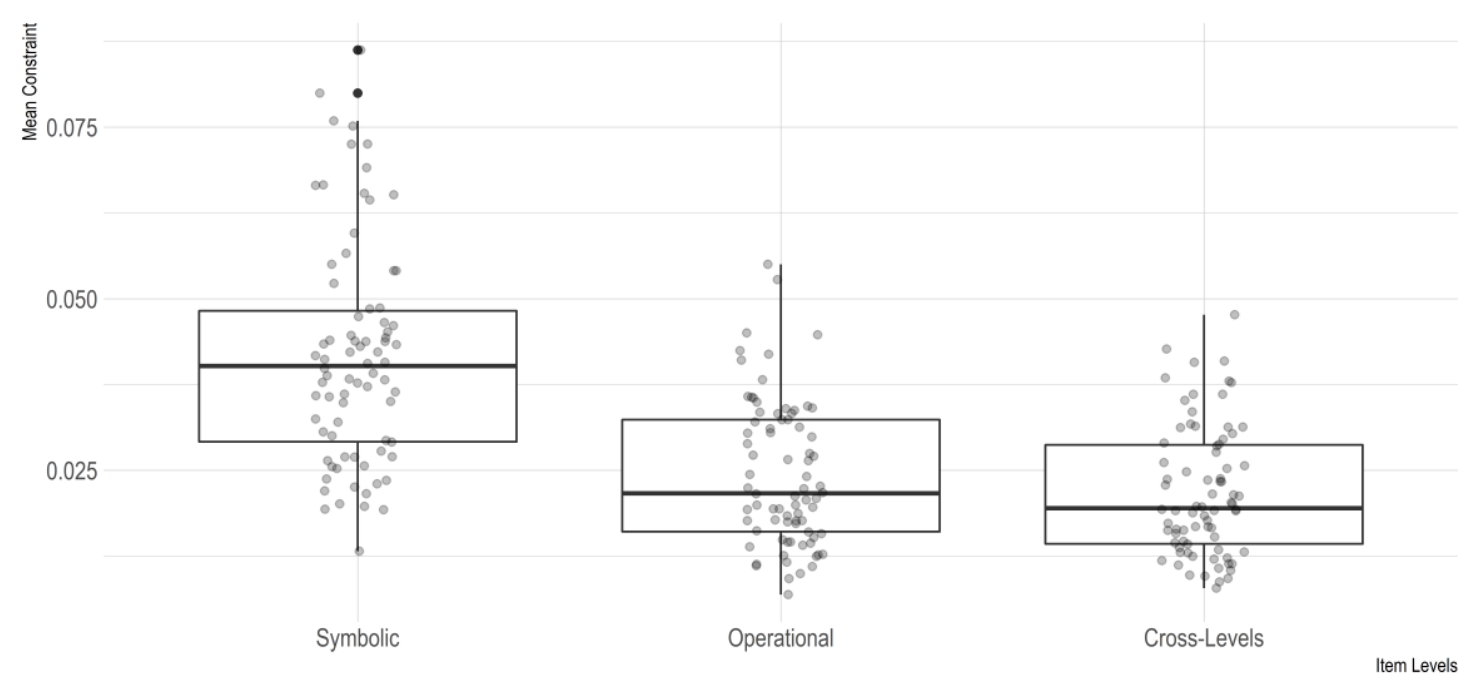

\section{Figure 5: Mean Constraint Across Different Item Levels}

Note: Each boxplot represents the distribution of mean constraint across different item pairs: "symbolic" refers to the correlations among symbolic items, "operational" refers to the correlations among operational items, and the "cross-levels" refers to the correlations between symbolic and operational items. Each point in the boxplot depicts the mean level of correlations (belief constraint) for a particular country.

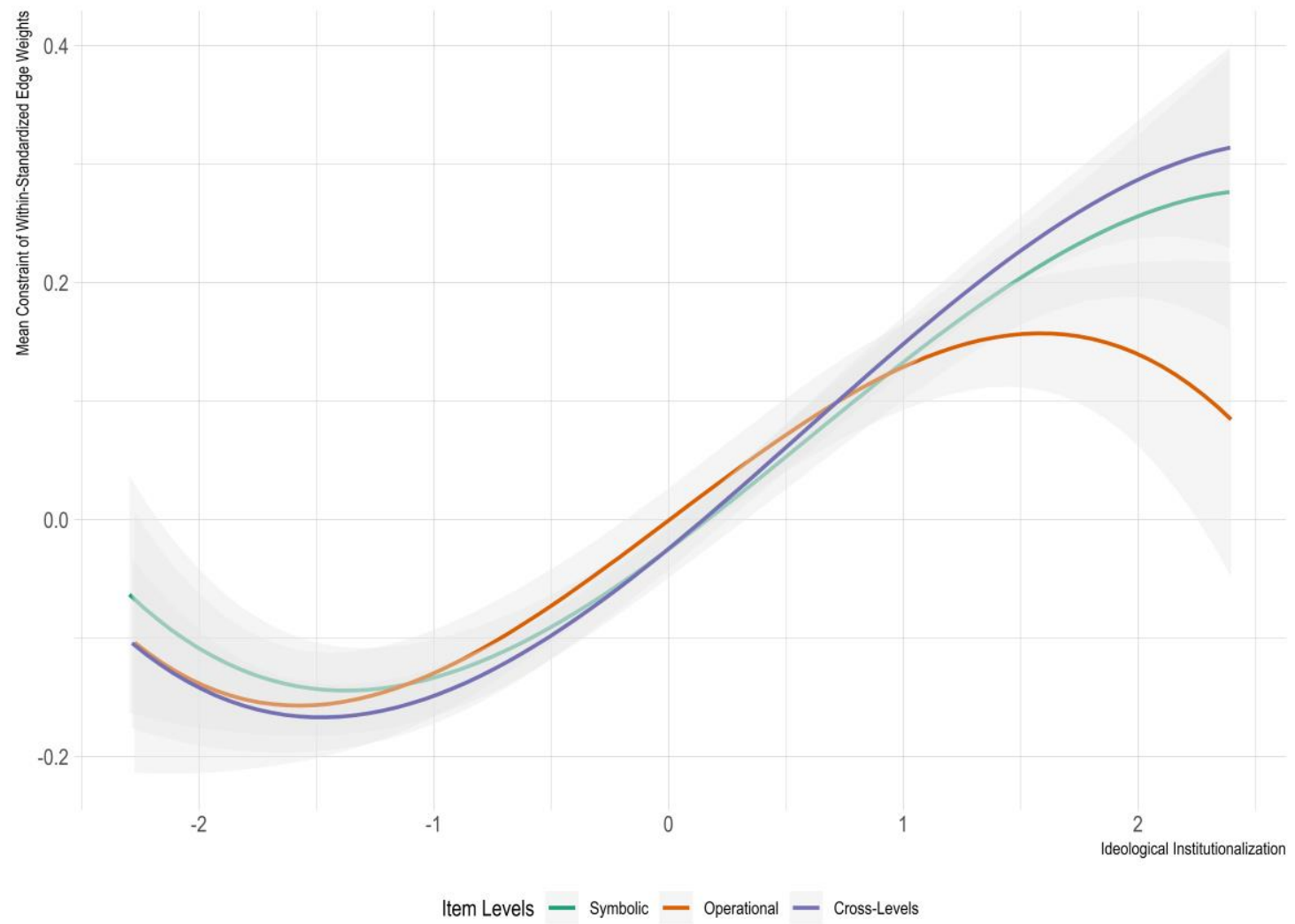

Figure 6: Mean Constraint Trajectories Across Different Item Levels

Note: The figure shows the cubic spline-smoothed functions of ideological institutionalization in three levels. 


\subsection{Population Heterogeneity and Educational Attainment}

One interesting result from the pooled regression models is the insignificance of the educational attainment variable. This is in contrast to the previous literature that consistently finds that the level of education predicts varying belief constraints (Converse 1964; Judd and Milburn 1980). I analyzed this pattern in supplemental investigations and found that ideological institutionalization and political activism mediate the bulk of educational influence. However, this does not resolve the question of educational attainment as the insignificance between countries does not mean that education has no effect within countries. The most important question is whether the trends still apply if we consider different educational groups within countries.

I first separated the respondents into three distinct groups according to their self-reported educational attainment: those with low education (lower-secondary at most), those with middle education (from upper-secondary to post-secondary non-tertiary) and those with high education (bachelor or more). Then, I selected the lower-educated and highly educated groups, collected the correlation coefficients for each group, and estimated the mean constraint levels. Consistent with the previous literature, the results show that people with high education have significantly more constrained belief systems than people with low education $(t=3.72, p<0.001)$.

Table 2 presents the pooled regression estimations across different educational groups. It is apparent that ideological institutionalization is still strongly associated with belief constraint. However, mean educational attainment becomes significant for the lower-educated group while political activism becomes insignificant. This is a surprising outcome. The results suggest that the national-level education, net of one's individual-level education, has a significant and positive effect on belief organization for those with low-education. Even though this research cannot provide definitive answers with regard to this outcome, the result seems consistent with the political field approach. It might be that a nationally high level of education might be bolstering public discussions, which in turn helps low-educated individuals to grab consistent attitudes. It 
is also possible that lower-educated individuals find more chance to incorporate consistent considerations from politically knowledgeable individuals through their local environments. Thus, whatever the underlying mechanism might be, lower-educated individuals might be benefiting from the political field with a relatively high educational composition.

Table 2: OLS Regression Models, Grouped by Educational Status

\begin{tabular}{lccc}
\hline \hline Predictors & All Groups & High Education & Low Education \\
\hline Ideological Institutionalization & $0.432^{* * *}$ & $0.429^{* * *}$ & $0.453^{* *}$ \\
& $(0.095)$ & $(0.107)$ & $(0.140)$ \\
Country-Level Political Activism & $0.277^{* *}$ & $0.477^{* * *}$ & 0.056 \\
& $(0.111)$ & $(0.125)$ & $(0.158)$ \\
Mean Educational Attainment & 0.077 & -0.162 & $0.360^{*}$ \\
& $(0.097)$ & $(0.115)$ & $(0.137)$ \\
Educational Group (Ref = High Education) & $-0.388^{* * *}$ & & \\
& $(0.109)$ & & + \\
Survey Instrument Controls & & + & 78 \\
\hline $\mathrm{N}$ & 156 & 78 & 0.31 \\
Adjusted $\mathrm{R}^{2}$ & 0.36 & 0.50 & + \\
\hline
\end{tabular}

Note: Coefficients are standardized. Heteroskedasticity-consistent standard errors are in parentheses. The missing countries are Andorra, Macau and Puerto Rico. All models control for the inclusion of political ideology, the mode of survey collection, sample size, and survey language. I clustered the standard errors at the country-level for M1. $* * * \mathrm{p}<0.001, * * \mathrm{p}<0.01, * \mathrm{p}<0.05$

\section{DISCUSSION}

In this article, I investigated the structure of political opinions in 78 countries to understand the cross-national differences in the organization of political beliefs. I claimed that political parties significantly predict how political views are organized, and consistent with the social constraint accounts (Converse 1964; Zaller 1992), I observed that an increased salience of political structure, particularly ideological institutionalization of political parties, is strongly associated with high constraint. These results are robust to a variety of controls, including political engagement among the populace, media differentiation, or educational attainment. Moreover, I showed that the results are not sensitive to sampling variability, item selection, and edge heterogeneity. 


\subsection{The Main Implications}

These findings have important implications for the public opinion literature, as well as political and cultural sociology. First, it proves vital to test the structure of opinions in the cross-national context. Up until now, most studies have focused on the United States, but the proposed mechanisms have not been adequately tested in other countries. Taking these studies forward should increase the validity and generalizability of the previous findings. Second, these results provide further support for the social constraint model (Converse 1964; Zaller 1992), showing that the differences in political fields have concrete implications for the organization of political beliefs. The previous literature relied on within-country variations to establish that political fields have an effect on belief constraints. Instead, I exploited between-country variations to validate these findings and complemented the literature with an extensive macro-scale examination.

Emphasizing the contextual sources of belief organization, this article also complements psychological and cognitive accounts of opinion structure, most of which derives from theories on constraint satisfaction on attitudes (Goldberg and Stein 2018; Keskintürk 2021; Rawlings 2020). Instead, these results show that cultural, political, and institutional differences can serve as fruitful channels for explaining the variation in belief networks. Combining social constraint accounts with work on psychological systems and identity (Brandt and Sleegers 2021), we can establish rigorous theories on the dynamics of opinion change and stability.

One crucial finding involves the differences across education. Using various measures of educational attainment, knowledge on politics, and political interest, Zaller (1992:21) claimed that these measures tap into an underlying propensity of "political awareness," which refers to "the extent to which an individual pays attention to politics and understands what he or she has encountered." Consistent with this description, individuals with low education have low belief constraint compared to individuals with high education in almost all countries. However, I also found that ideological institutionalization has similar effects across educational groups. 
Moreover, this contextual effect seems stronger compared to other explanations.

\subsection{Limitations and Future Directions}

However, this article does have its limitations. First, examining the structure of belief systems does not provide causal identification nor does it produce definite predictions. This problem is exacerbated if we consider the fact that this article uses cross-sectional data, meaning that there is no temporal dimension to evaluate the replicability of belief networks, as well as the direction and causal effect of the ideological institutionalization. Thus, it is imperative for future research to incorporate the questions of time and causal identification into the analyses. The utilization of panel studies and careful identification strategies would be much valuable.

Second, the "limits" of belief systems should receive more attention. In this article, I used political beliefs covered in the EVS/WVS, which is why the analyses are limited to these items. However, incorporating untapped political beliefs and even beliefs that are not visibly pertinent to political questions can change the previous conclusions. This problem is intricately tied with the question of how belief systems are generated and what their limits are. Using an extensive set of items from the GSS, DellaPosta (2020) was able to relax this assumption, covering more than one belief domain. However, considering the fact that the design and execution of surveys can significantly affect the responses (Alwin and Krosnick 1991), collecting cross-national data seems difficult. Hence, future studies can experiment with this problem, adjudicating whether an extensive set of items or theoretically limited belief measures are more reliable.

Following the final points, the third limitation pertains to the simplifying assumption that the generation of belief systems follows the same logics in all populations. Whether the belief systems of subpopulations differ is an empirical question that should receive strong focus from cultural sociologists. One possible extension for this question might be the inclusion of demographic variables and possible predictors in the network design, allowing to explicitly measure the potential effects of social positions and personal dispositions on belief systems. 


\section{REFERENCES}

Alesina, Alberto, Arnaud Devleeschauwer, William Easterly, Sergio Kurlat, and Romain Wacziarg. 2003. “Fractionalization.” Journal of Economic Growth 8(2):155-94.

Alwin, Duane F., and Jon A. Krosnick. 1991. "The Reliability of Survey Attitude Measurement: The Influence of Question and Respondent Attributes.” Sociological Methods \& Research 20(1):139-81.

Ansolabehere, Stephen, Jonathan Rodden, and James M. Snyder. 2008. “The Strength of Issues: Using Multiple Measures to Gauge Preference Stability, Ideological Constraint, and Issue Voting.” American Political Science Review 102(2):215-32.

Baldassarri, Delia, and Andrew Gelman. 2008. "Partisans without Constraint: Political Polarization and Trends in American Public Opinion.” American Journal of Sociology 114(2):408-46.

Baldassarri, Delia, and Amir Goldberg. 2014. "Neither Ideologues nor Agnostics: Alternative Voters' Belief System in an Age of Partisan Politics.” American Journal of Sociology 120(1):45-95.

Bizarro, Fernando, Allen Hicken, and Darin Self. 2020. "The V-Dem Party Institutionalization Index: A New Global Indicator (1900-2018).” Working Paper, The Variety of Democracy Institute.

Boutyline, Andrei. 2022. "Holding A Position: Public Opinion as Cognition in a Disorganized Field." SocArxiv.

Boutyline, Andrei, and Stephen Vaisey. 2017. "Belief Network Analysis: A Relational Approach to Understanding the Structure of Attitudes.” American Journal of Sociology 122(5):1371-1447.

Brandt, Mark J., Chris G. Sibley, and Danny Osborne. 2019. "What Is Central to Political Belief System Networks?” Personality and Social Psychology Bulletin 45(9):1352-64.

Brandt, Mark J., and Willem W. A. Sleegers. 2021. "Evaluating Belief System Networks as a Theory of Political Belief System Dynamics.” Personality and Social Psychology Review 25(2):159-85.

Carmines, Edward G., and James A. Stimson. 1986. "On the Structure and Sequence of Issue Evolution." American Political Science Review 80(3):901-20.

Converse, Philip E. 1964. "The Nature of Belief Systems in Mass Publics." Pp. 206-61 in Ideology and Discontent, edited by D. Apter. Princeton: Princeton University Press.

Coppedge, Michael, John Gerring, Carl Henrik Knutsen, Staffan I. Lindberg, Jan Teorell, David Altman, Michael Bernhard, M. Steven Fish, Adam Glynn, Allen Hicken, Anna Luhrmann, Kyle L. Marquardt, Kelly McMann, Pamela Paxton, Daniel Pemstein, Brigitte Seim, Rachel Sigman, Svend-Erik Skaaning, Jeffrey Staton, Agnes Cornell, Lisa Gastaldi, Haakon Gjerløw, Valeriya Mechkova, Johannes Von Römer, Aksel Sundtröm, Eitan Tzelgov, Lica Uberti, Yi-Ting Wang, Tore Wig, and Daniel Ziblatt. 2020. "V-Dem Dataset 
V10." Varieties of Democracy (V-Dem) Project.

DellaPosta, Daniel. 2020. "Pluralistic Collapse: The ‘Oil Spill’ Model of Mass Opinion Polarization.” American Sociological Review 85(3):507-36.

DiMaggio, Paul. 1997. “Culture and Cognition.” Annual Review of Sociology 23:263-87.

EVS/WVS. 2020. "European Values Study and World Values Survey: Joint EVS/WVS 2017-2021 Dataset (Joint EVS/WVS).” JD Systems Institute \& WVSA. Dataset Version 1.0.0.

Fishman, Nic, and Nicholas T. Davis. 2021. "Change We Can Believe In: Structural and Content Dynamics within Belief Networks.” American Journal of Political Science.

Gallagher, Michael. 2020. "Election Indices Dataset."

Goldberg, Amir. 2011. "Mapping Shared Understandings Using Relational Class Analysis: The Case of the Cultural Omnivore Reexamined." American Journal of Sociology 116(5):1397-1436.

Goldberg, Amir, and Sarah K. Stein. 2018. "Beyond Social Contagion: Associative Diffusion and the Emergence of Cultural Variation." American Sociological Review 83(5):897-932.

Gordon, Stacy B., and Gary M. Segura. 1997. "Cross-National Variation in the Political Sophistication of Individuals: Capability or Choice?” Journal of Politics 59(1):126-47.

Goren, Paul, Christopher M. Federico, and Miki Caul Kittilson. 2009. "Source Cues, Partisan Identities, and Political Value Expression.” American Journal of Political Science 53(4):805-20.

Jost, John T., Christopher M. Federico, and Jaime L. Napier. 2009. "Political Ideology: Its Structure, Functions, and Elective Affinities." Annual Review of Psychology 60(1):307-37.

Judd, Charles M., and Jon A. Krosnick. 1982. "Attitude Centrality, Organization, and Measurement.” Journal of Personality and Social Psychology 42(3):436-47.

Judd, Charles M., and Michael A. Milburn. 1980. "The Structure of Attitude Systems in the General Public: Comparisons of a Structural Equation Model.” American Sociological Review 45(4):627-43.

Keskintürk, Turgut. 2021. "Religious Belief Alignment: The Structure of Cultural Beliefs from Adolescence to Emerging Adulthood." Poetics 90:101591.

Kiley, Kevin, and Stephen Vaisey. 2020. "Measuring Stability and Change in Personal Culture Using Panel Data." American Sociological Review 85(3):477-506.

Kozlowski, Austin C., and James P. Murphy. 2020. "Issue Alignment and Partisanship in the American Public: Revisiting the 'Partisans without Constraint' Thesis.” Social Science Research 94:102498.

Laakso, Markku, and Rein Taagepera. 1979. “"Effective' Number of Parties.” Comparative Political Studies 
12(1):3-27.

Lindner, Andrew M., and Jason N. Houle. 2021. "Are All Politics National? County-Level Social Contexts and Inequality Remediation Attitudes, 2006 to 2012." Socius: Sociological Research for a Dynamic World 7:114.

Lizardo, Omar. 2019. "Specifying the 'What' and Separating the 'How': Doings, Sayings, Codes, and Artifacts as the Building Blocks of Institutions.” Pp. 217-34 in Microfoundations of Institutions. Vol. 65A, Research in the Sociology of Organizations, edited by P. Haack, J. Sieweke, and L. Wessel. Emerald Publishing Limited.

Martin, John Levi. 2002. "Power, Authority, and the Constraint of Belief Systems." American Journal of Sociology 107(4):861-904.

Martin, John Levi, and Matthew Desmond. 2010. "Political Position and Social Knowledge." Sociological Forum 25(1):1-26.

Nie, Norman H., and Kristi Andersen. 1974. "Mass Belief Systems Revisited: Political Change and Attitude Structure." The Journal of Politics 36(3):540-91.

Peffley, Mark A., and Jon Hurwitz. 1985. "A Hierarchical Model of Attitude Constraint." American Journal of Political Science 29(4):871-90.

Raftery, Adrian E. 1995. "Bayesian Model Selection in Social Research.” Sociological Methodology 25:111-63.

Rawlings, Craig M. 2020. "Cognitive Authority and the Constraint of Attitude Change in Groups." American Sociological Review 85(6):992-1021.

Slothuus, Rune, and Martin Bisgaard. 2021. "How Political Parties Shape Public Opinion in the Real World." American Journal of Political Science 65(4):896-911.

Swidler, Ann. 1986. "Culture in Action: Symbols and Strategies.” American Sociological Review 51(2):273-86.

Zaller, John R. 1992. The Nature and Origins of Mass Opinion. Cambridge: Cambridge University Press.

Zaller, John R., and Stanley Feldman. 1992. “A Simple Theory of the Survey Response: Answering Questions versus Revealing Preferences." American Journal of Political Science 36(3):579-616. 


\section{APPENDIX}

Table A1 provides the full list of countries covered in EVS/WVS, along with their sample sizes. In Table A2, I document the full list of question labels and descriptions. Table A3 provides the descriptive statistics of items used in the regression models.

Table A1: The Characteristics of Countries

\begin{tabular}{|c|c|c|c|}
\hline Country/Territory & Shortened Name & Survey & Sample Size \\
\hline Albania & $\mathrm{AL}$ & EVS & 1435 \\
\hline Andorra & $\mathrm{AD}$ & WVS & 1004 \\
\hline Argentina & AR & WVS & 1003 \\
\hline Armenia & $\mathrm{AM}$ & EVS & 1500 \\
\hline Australia & $\mathrm{AU}$ & WVS & 1813 \\
\hline Austria & AT & EVS & 1644 \\
\hline Azerbaijan & $\mathrm{AZ}$ & EVS & 1800 \\
\hline Bangladesh & $\mathrm{BD}$ & WVS & 1200 \\
\hline Belarus & BY & EVS & 1548 \\
\hline Bolivia & $\mathrm{BO}$ & WVS & 2067 \\
\hline Bosnia and Herzegovina & BA & EVS & 1724 \\
\hline Brazil & $\mathrm{BR}$ & WVS & 1762 \\
\hline Bulgaria & BG & EVS & 1558 \\
\hline Canada & $\mathrm{CA}$ & WVS & 4018 \\
\hline Chile & CL & WVS & 1000 \\
\hline China & $\mathrm{CN}$ & WVS & 3036 \\
\hline Colombia & $\mathrm{CO}$ & WVS & 1520 \\
\hline Croatia & HR & EVS & 1487 \\
\hline Cyprus & CY & WVS & 1000 \\
\hline Czechia & $\mathrm{CZ}$ & EVS & 1811 \\
\hline Denmark & DK & EVS & 3362 \\
\hline Ecuador & $\mathrm{EC}$ & WVS & 1200 \\
\hline Egypt & EG & WVS & 1200 \\
\hline Estonia & $\mathrm{EE}$ & EVS & 1304 \\
\hline Ethiopia & ET & WVS & 1230 \\
\hline Finland & FI & EVS & 1199 \\
\hline France & FR & EVS & 1870 \\
\hline Georgia & GE & EVS & 2194 \\
\hline Germany & DE & EVS & 2170 \\
\hline Germany & $\mathrm{DE}$ & WVS & 1528 \\
\hline Great Britain & GB & EVS & 1788 \\
\hline Greece & GR & WVS & 1200 \\
\hline Guatemala & GT & WVS & 1203 \\
\hline Hong Kong SAR & HK & WVS & 2075 \\
\hline Hungary & $\mathrm{HU}$ & EVS & 1514 \\
\hline Iceland & IS & EVS & 1624 \\
\hline Indonesia & ID & WVS & 3200 \\
\hline Iran & IR & WVS & 1499 \\
\hline Iraq & IQ & WVS & 1200 \\
\hline Italy & IT & EVS & 2277 \\
\hline
\end{tabular}




\begin{tabular}{|c|c|c|c|}
\hline Japan & JP & WVS & 1353 \\
\hline Jordan & $\mathrm{JO}$ & WVS & 1203 \\
\hline Kazakhstan & $\mathrm{KZ}$ & WVS & 1276 \\
\hline Kyrgyzstan & $\mathrm{KG}$ & WVS & 1200 \\
\hline Lebanon & LB & WVS & 1200 \\
\hline Lithuania & $\mathrm{LT}$ & EVS & 1448 \\
\hline Macau SAR & MO & WVS & 1023 \\
\hline Malaysia & MY & WVS & 1313 \\
\hline Mexico & MX & WVS & 1739 \\
\hline Montenegro & ME & EVS & 1003 \\
\hline Myanmar & MM & WVS & 1200 \\
\hline Netherlands & NL & EVS & 2404 \\
\hline New Zealand & $\mathrm{NZ}$ & WVS & 1057 \\
\hline Nicaragua & NI & WVS & 1200 \\
\hline Nigeria & $\mathrm{NG}$ & WVS & 1237 \\
\hline North Macedonia & MK & EVS & 1117 \\
\hline Norway & $\mathrm{NO}$ & EVS & 1122 \\
\hline Pakistan & $\mathrm{PK}$ & WVS & 1995 \\
\hline Peru & $\mathrm{PE}$ & WVS & 1400 \\
\hline Philippines & $\mathrm{PH}$ & WVS & 1200 \\
\hline Poland & $\mathrm{PL}$ & EVS & 1352 \\
\hline Portugal & PT & EVS & 1215 \\
\hline Puerto Rico & PR & WVS & 1127 \\
\hline Romania & $\mathrm{RO}$ & EVS & 1613 \\
\hline Romania & RO & WVS & 1257 \\
\hline Russia & $\mathrm{RU}$ & EVS & 1825 \\
\hline Russia & $\mathrm{RU}$ & WVS & 1810 \\
\hline Serbia & $\mathrm{RS}$ & EVS & 1499 \\
\hline Serbia & $\mathrm{RS}$ & WVS & 1046 \\
\hline Singapore & SI & WVS & 2012 \\
\hline Slovakia & SK & EVS & 1432 \\
\hline Slovenia & SI & EVS & 1075 \\
\hline South Korea & KR & WVS & 1245 \\
\hline Spain & $\mathrm{ES}$ & EVS & 1209 \\
\hline Sweden & $\mathrm{SE}$ & EVS & 1194 \\
\hline Switzerland & $\mathrm{CH}$ & EVS & 3174 \\
\hline Taiwan ROC & TW & WVS & 1223 \\
\hline Tajikistan & $\mathrm{TJ}$ & WVS & 1200 \\
\hline Thailand & $\mathrm{TH}$ & WVS & 1500 \\
\hline Tunisia & $\mathrm{TN}$ & WVS & 1208 \\
\hline Turkey & $\mathrm{TR}$ & WVS & 2415 \\
\hline Ukraine & UA & WVS & 1289 \\
\hline United States & US & WVS & 2596 \\
\hline Vietnam & $\mathrm{VN}$ & WVS & 1200 \\
\hline Zimbabwe & $\mathrm{ZW}$ & WVS & 1215 \\
\hline
\end{tabular}


Table A2: Items Used in the Belief Networks

\begin{tabular}{|c|c|c|}
\hline Nodes & Question Labels & Question Level \\
\hline A124_02 & Neighbors: People of a Different Race & Symbolic \\
\hline A124_06 & Neighbors: Immigrants/Foreign Workers & Symbolic \\
\hline B008 & Protecting Environment vs Economic Growth & Operational \\
\hline $\mathrm{C} 001$ & Jobs: Men over Women & Operational \\
\hline $\mathrm{C} 002$ & Jobs: Nation over Immigrants & Operational \\
\hline D059 & Men Are Better Political Leaders than Women & Symbolic \\
\hline D060 & University More Important for Boys than Girls & Symbolic \\
\hline D061 & The Children Suffer with Working Mother & Symbolic \\
\hline D078 & Men Are Better Business Execs than Women & Symbolic \\
\hline E033 & Self-Positioning in Political Scale & Symbolic \\
\hline E035 & Income Should Be Equal & Operational \\
\hline E036 & Private vs State Ownership of Business & Operational \\
\hline E037 & Government's Responsibilities & Operational \\
\hline E039 & Competition Good or Harmful & Operational \\
\hline E114 & Political System: Strong Leadership & Symbolic \\
\hline E115 & Political System: Experts & Symbolic \\
\hline E117 & Political System: Democratic Politics & Symbolic \\
\hline E224 & Governments Tax The Rich And Subsidize The Poor & Operational \\
\hline E225 & Religious Authorities Interpret The Laws & Symbolic \\
\hline E226 & People Choose Their Leaders In Free Elections & Symbolic \\
\hline E227 & People Receive State Aid For Unemployment & Operational \\
\hline E229 & Civil Rights Protect People's Liberty Against Oppression & Operational \\
\hline E233 & Women Have The Same Rights As Men & Operational \\
\hline E233A & The State Makes People's Incomes Equal & Operational \\
\hline E233B & People Obey Their Rulers & Symbolic \\
\hline E235 & Importance of Democracy & Symbolic \\
\hline F120 & Ethical Values and Norms: Abortion & Operational \\
\hline F144_02 & Ethical Values and Norms: Death Penalty & Operational \\
\hline G052 & Evaluate the Impact of Immigrants Over Country & Operational \\
\hline G007_35_B & Trust: People of Another Religion & Symbolic \\
\hline G007_36_B & Trust: People of Another Nationality & Symbolic \\
\hline conf & Confidence in Political Institutions (E069_01-E069_20) & Symbolic \\
\hline
\end{tabular}


Table A3: Descriptive Statistics for Predictors Used in the Regression Models

\begin{tabular}{lcccc}
\hline \hline Predictors & Mean & SD & Min & Max \\
\hline Ideological Institutionalization & 1.28 & 0.83 & -0.59 & 3.26 \\
Country-Level Political Activism & 1.60 & 0.27 & 1.09 & 2.16 \\
Mean Educational Attainment & 3.58 & 0.79 & 1.85 & 4.94 \\
Alternative Sources of Information & 0.74 & 0.25 & 0.05 & 0.98 \\
Country-Level Civic Membership & 0.15 & 0.10 & 0.01 & 0.39 \\
The $N$ of Effective Political Parties & 5.01 & 3.46 & 1.00 & 21.67 \\
Country-Level Political Polarization & -0.20 & 1.27 & -3.05 & 2.61 \\
Ethnic Fractionalization & 0.36 & 0.22 & 0.02 & 0.85 \\
Religious Fractionalization & 0.37 & 0.23 & 0.01 & 0.85 \\
\hline
\end{tabular}

